\title{
Budgetary Consequences of the 7th NFC Award
}

\author{
HAFIZ A. PASHa, Aisha G. PASHA, and MUHAMMAD IMRAN
}

\section{INTRODUCTION}

The 7th NFC Award of 2009 has generally been recognised as a historic achievement of the present democratically elected government. Not only was consensus achieved after a gap of 12 years among the Federal and Provincial Governments but major strides have also been made in furthering the process of fiscal decentralisation in the country. The Federal Government will be transferring substantially more resources to the provinces by a major enhancement in the collective share of the latter from the divisible pool taxes. In addition, the provinces have agreed to a horizontal sharing formula that includes multiple criteria and promises greater fiscal equalisation in favour of the more backward provinces. Straight transfers have also been rationalised and the Federal Government has agreed to pay in instalments the substantial arrears that had accumulated under different heads.

The first set of post-NFC budgets have been announced for 2010-11. Some of the consequences of the Award have become visible. The Federal Government is pushing for a strong fiscal adjustment by reducing the target for the consolidated fiscal deficit from 6.3 percent of the GDP in 2009-10 to 4 percent in 2010-11, as part of the agreement in the on-going SBA with the IMF. This is predicated, first, on a virtually zero growth in Federal current expenditure and a modest growth in development expenditure coupled with a relatively strong fiscal effort and, second, on the inability of the provinces to absorb fully the large post-NFC increase in transfers in the short run, thereby leading to a large build up in cash balances of upto one percent of the GDP.

But, a number of issues have risen already with regard to the implications of the radical change in inter-governmental relations after the 7th NFC Award. Has the underlying structural fiscal deficit been raised once-and-for-all by the Award? Can the Federal Government restrain the real growth in its expenditures given the downward rigidities in security expenditure, debt servicing, costs of civil administration and increasingly now in subsidies and transfer payments? What is the incentive for the Federal Government in a democratic dispensation to raise the tax burden and incur the political costs thereof while transferring a major part of the additional revenues to the Provincial Governments, which may be on the other side of the political divide as is the case currently in the largest province, Punjab? Given the quantum jump in transfers are the provinces likely to show financial discipline or engage in runaway spending and

Hafiz A. Pasha <hafiz.pasha@gmail.com> is Dean, School of Social Sciences. Aisha G. Pasha <aisha.pasha@yahoo.com> is Director of Institute of Public Policy and Muhammad Imran <imran.muhammad86@hotmail.com> is Research Associate of IPP respectively of the Beaconhouse National University, Lahore. 
waste scarce public resources? Should incentives be put in place on top of the Award to promote greater fiscal effort and economy in current expenditure by provincial governments?

The purpose of this paper is to offer an initial answer to these questions. Using theoretical models to capture fiscal decisions by Federal and Provincial Governments, the paper aims to study historically the nature of federal and provincial responses respectively to changes in inter-governmental fiscal relations in the aftermath of various awards. Section 2 sets up a theoretical model for fiscal behaviour by the Federal Government and the corresponding model of provincial governments. Section 3 presents estimates of the behavioural equations. Section 4 quantifies the likely impact of the NFC Award on the consolidated fiscal deficit. Section 5 gives the key policy implications of the research findings. Finally, in Section 6 are presented the conclusions.

\section{THE THEORETICAL FRAMEWORK}

We first develop the theoretical framework for analysis of the fiscal behaviour by the Federal Government.

\section{Federal Government}

The approach generally adopted is to assume that politicians /officials maximise the utility of a typical citizen subject to a budget constraint [Slack (1980); Henderson (1968); Ghaus and Pasha (1994)]. Utility is a function of the quantity of goods and services provided by the government and on the level of consumption of private goods. Ghaus, et al. (1994) have demonstrated that for every rupee increase in transfers to provincial governments there is a 61 paisa increase in expenditure.

We designate the following: $Y=$ income, $R_{f}=$ tax revenue, $\bar{N}_{f}=$ non-tax revenue (exogeneously given), $\bar{D}_{f}=$ target level of deficit financing by borrowing. All variables are measured in real per capita terms. ${ }^{1}$ If $\beta$ is the proportion of tax revenues retained by the Federal Government as per the operative NFC Award, then

$$
\begin{array}{lllllll}
E_{f}=\beta R_{f}+\bar{N}_{f}+\bar{D}_{f} & \ldots & \ldots & \ldots & \ldots & \ldots & \ldots
\end{array}
$$

Where $E_{f}=$ level of public expenditure in real per capita terms.

The utility function of the Federal Government is given by

$$
U=\left(Y-R_{f}-\bar{N}_{f}-Y_{o f}\right)^{\alpha} \quad\left(E_{f}-E_{o f}\right)^{1-\alpha}, 0<\alpha<1 \quad \ldots \quad \ldots \quad \ldots
$$

This is analogous to the Stone-Geary utility function.

This utility is maximised with respect to $R_{f}$ and

$$
\frac{\partial U}{\partial R_{f}}=-\frac{\alpha}{\left(Y-R_{f}-\bar{N}_{f}-Y_{o f}\right.}+\frac{(1-\alpha) \beta}{\beta R_{f}+\bar{N}_{f}+\bar{D}_{f}-E_{o f}}=0
$$

\footnotetext{
${ }^{1}$ Price indices for public and private goods are assumed to be the same.
} 
which yields

$$
\beta R_{f}=(1-\alpha) \beta\left(Y=Y_{o f}\right)-[\alpha+(1-\alpha) \beta] \bar{N}_{f}-\alpha \bar{D}_{f}+\alpha E_{o f} \quad \ldots \quad \ldots
$$

and

$$
\frac{\partial(\beta R)}{\partial \beta}=(1-\alpha)\left[Y-Y_{o f}-\bar{N}_{f}\right]>0
$$

Similarly,

$$
\frac{\partial(\beta R)}{\partial Y}>0 \frac{\partial(\beta R)}{\partial \bar{N}}>0
$$

Therefore, the higher $\beta$ is the larger the magnitude of revenues retained, $\beta R$, by the Federal Government.

From (3) we also have that

$$
R_{f}=(1-\alpha)\left(Y-Y_{o}\right)-\left[(1-\alpha)+\frac{\alpha}{\beta}\right] \bar{N}-\frac{\alpha}{\beta} \bar{D}+\frac{\alpha}{\beta} E_{o} \quad \ldots \quad \ldots \quad \ldots
$$

and

$$
\frac{\partial R_{f}}{\partial \beta}=\frac{\alpha}{\beta^{2}}\left[\bar{N}_{f}+\bar{D}_{f}-E_{0 f}\right]_{>}^{<0}
$$

This is important finding. The impact on the level of fiscal effort of the Federal Government as measured by the level of tax revenues, $R$, of changes in $\beta$ is ambiguous. If the minimum level, $E_{o}$, of public expenditure exceeds the sum of non-tax revenues, $N_{f}$, and deficit financing, $\bar{D}_{f}$, then a fall in $\beta$ following the 7th NFC Award is likely to stimulate a positive response by the Federal Government in terms of raising the level of tax revenues.

From (1) and (3) we also obtain that

$$
E_{f}=(1-\alpha) \beta\left(Y-Y_{o f}\right)-(1-\alpha)(1-\beta) \bar{N}_{f}+(1-\alpha) \bar{D}_{f}+\alpha E_{o f} \quad \ldots \quad \ldots
$$

and

$$
\frac{\partial E_{f}}{\partial \beta}=(1-\alpha)\left[Y-Y_{o f}-\bar{N}_{f}>0\right.
$$

Similarly,

$$
\frac{\partial E_{f}}{\partial Y}>0, \quad \frac{\partial E_{f}}{\partial \bar{N}_{f}}>0
$$

The target deficit can be expressed as

$$
\begin{array}{llllllll}
\bar{D}_{f}=\alpha_{0}+\alpha_{1} y & \ldots & \ldots & \ldots & \ldots & \ldots & \ldots & \ldots
\end{array}
$$


At this stage, we allow for a lagged adjustment process to the desired fiscal magnitudes. That is

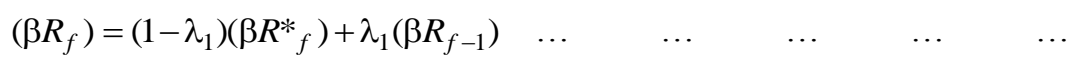

Where $\left(\beta R_{f}^{*}\right)$ is given by (3). Similarly,

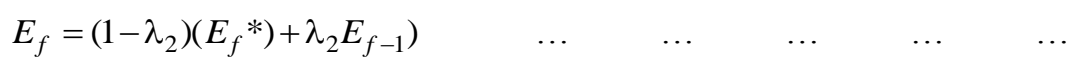

It can be seen from (7) and (8) that if $\left(\lambda_{2}>\lambda_{1} 1\right)$, due to downward rigidities in expenditure, then the deficit rises temporarily of the Federal Government following the Award.

We have finally that he equations to be estimated from the data are as follows:

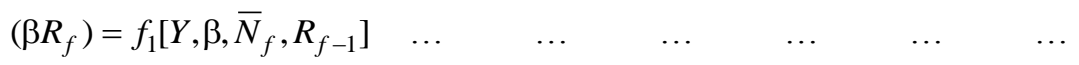

and

$$
E_{f}=f_{2}\left[Y, \beta, \bar{N}_{f}, E_{f-1}\right] \quad \ldots \quad \ldots \quad \ldots \quad \ldots \quad \ldots
$$

We turn now to the theoretical framework for the Provincial Governments.

\section{Provincial Governments}

In this case, we use the suffix $p$ instead of $f$.

The expenditure level of the Provincial Governments is given by

$$
E_{p}=T F+R_{p}+\bar{N}_{p}+\bar{D}_{p} \quad \ldots \quad \ldots \quad \ldots \quad \ldots \quad \ldots \quad \ldots
$$

Where $T F$ is the total divisible pool transfer and

$$
T F=(1-\beta) R_{1 f}
$$$$
\cdots
$$$$
\cdots
$$$$
\text { . } \quad \cdots
$$

The utility function of the provincial governments is given by

$$
U=\left(Y-R_{p}-\bar{N}_{p}-Y_{O P}\right)^{\theta}\left(E_{p}-E_{O P}\right)^{1-\theta}, 0<\theta<1
$$

The utility is maximised with respect to $R_{p}$ and

$$
\frac{\partial U}{\partial R_{p}}=-\frac{\theta}{y-R_{p}-\bar{N}_{p}-y_{o p}}+\frac{1-\theta}{R F+R_{p}+\bar{N}_{p}+\bar{D}_{p}-E_{O P}}
$$

Which leads to

$$
R_{p}=(1-\theta)\left(y-y_{o}\right)-\theta T F-\theta \bar{D}_{p}+\theta E_{O P}-\bar{N}_{P}
$$

and

$$
\frac{\partial R_{P}}{\partial Y F}=-\theta<0
$$


This implies that higher transfers lead to some slackening of fiscal effort by provincial governments.

Also,

$$
E_{p}=(1-\theta)\left(y-y_{o}\right) T F+(1-\theta) D_{P}+\theta E_{O P} \quad \ldots \quad \ldots \quad \ldots \quad \ldots \quad \ldots
$$

and

$$
\frac{\partial E_{P}}{\partial T F}=(1-\theta)>0
$$

As expected, higher transfers are accompanied by a rise in expenditure by provincial governments. As in the case of the Federal Government, we postulate in the case of Provincial Governments that there is a lagged process of adjustment to desired levels of own tax revenue and expenditure following the NFC Award.

\section{ESTIMATED RESULTS}

The respective expenditure and revenue equations for the federal and provincial governments (combined) have been estimated by the use of the OLS technique for the period, 1987-88 to 2009-10, during the tenure of which three NFC awards have been announced. All variables are measured in real per capita terms to avoid problems of non-stationarity and spurious correlations. The results obtained are described below.

\section{Federal Government}

Tax Revenues: As shown in Table 1, tax revenues (RFDPTX) of the Federal Government have a negative relationship with the share of revenues (BETA) retained from the divisible pool. Therefore, historically the federal government has tended to enhance its fiscal effort in the aftermath of awards which mandated larger transfers to the provinces. A similar response can also be expected after the 7th NFC Award, which has led to a big decline in BETA. Also, it appears that a one rupee increase in non-tax revenues leads to a decline in fiscal effort of almost 34 paisas.

Table 1

Results of Regression Analysis on Determinants of Federal Budgetary Magnitudes (All Variables Measured in Real Per Capita Terms)

\begin{tabular}{lccc}
\hline & $\begin{array}{c}\text { Tax } \\
\text { Revenue }\end{array}$ & $\begin{array}{c}\text { Current } \\
\text { Expenditure }\end{array}$ & $\begin{array}{c}\text { Development } \\
\text { Expenditure }\end{array}$ \\
\hline Variable $^{\mathrm{a}}$ & (RFDPTX) & (RFCE) & $(\mathrm{RFDE})$ \\
Constant & $1187.5(2.624)^{*}$ & $1002.5(3.477)^{*}$ & $-751.6(-1.796)^{*}$ \\
Per Capita Income (RPCY) & $0.085(9.541)^{*}$ & $0.046(3.475)^{*}$ & $0.010(2.372)^{*}$ \\
Share of Divisible Pool Retained (BETA) & $-864.1(-1.748)^{* *}$ & - & $1298.0(2.644)^{*}$ \\
Federal Non-Tax Revenues (FNTR) & $-0.335(-2.337)^{*}$ & - & - \\
Lagged Dependent Variable & - & $0.328(2.681)^{*}$ & $0.472(5.045)^{*}$ \\
$\mathrm{R}^{2}$ & 0.969 & 0.921 & 0.864 \\
D-W & 2.230 & 2.464 & 2.366 \\
\hline Figures in brackets are $t$-ratios. & & & \\
a For individual equations, one or two specific dummy variables have been used to capture outlier values. Only \\
$\quad$ significant variables are included.
\end{tabular}


Non-tax Revenues: These are assumed to be exogeneously determined.

Current Expenditure: Current Expenditure of the Federal Government appears to be largely invariant with respect to the share, BETA, in the divisible pool. As highlighted earlier, there are strong downward rigidities with respect to expenditures on debt servicing, defence, general administration etc.

This demonstrated inability of the Federal Government to contract, following an Award which transfers more resources to the provinces, is the basic behavioural assymetry which could lead to an increase in the underlying structural fiscal deficit. The other part of this assymetry is the likely rapid expansion in provincial budgets following the receipt of larger transfers.

Development Expenditure: Development expenditure of the Federal Government does appear to be responsive to the availability of resources, as indicated by the magnitude of BETA. However, there is a process of lagged adjustment here as the coefficient of the previous years' level of development expenditure is large and significant. This implies that the federal PSDP will take some time to come down to the desired size given the fall in growth of net revenue receipts in the first year after the 7 th NFC Award.

\section{Provincial Governments}

Tax Revenues: As shown in Table 2, there is a negative relationship, as hypothesised, between provincial own tax revenues and the level of transfers from the divisible pool. The provinces are inclined to slacken their fiscal effort in the event of a favourable award, like the latest dispensation. This is another factor which contributes to an increase in the consolidated fiscal deficit. However, the magnitude of the behavioural response is small. A one rupee increase in transfers leads to five paisa fall in provincial tax revenues.

Table 2

Results of Regression Analysis on Determinants of Provincial Budgetary Magnitudes (All Variables in Real Per Capita Terms)

\begin{tabular}{lccc}
\hline & $\begin{array}{c}\text { Tax } \\
\text { Revenues }\end{array}$ & $\begin{array}{c}\text { Current } \\
\text { Expenditure }\end{array}$ & $\begin{array}{c}\text { Development } \\
\text { Expenditure }\end{array}$ \\
\hline Variable $^{\mathrm{a}}$ & $(\mathrm{RPTR})$ & $(\mathrm{RPCE})$ & $(\mathrm{RFDE})$ \\
Constant & $21.5(1.006)$ & $-87.6(-0.687)$ & $-200.1(-1.621)$ \\
Per Capita Income (RPCY) & $0.006(4.341)^{*}$ & $0.027(3.139)^{*}$ & $0.010(1.994)^{* *}$ \\
Transfers from Divisible Pool (RDPTRF) & $-0.049(-2.101)$ & $0.402(2.513)^{*}$ & - \\
Revenue Surplus (RDPTRF- & & & \\
$\quad$ RPCE+RPTR+RPNTR) & - & - & $0.376(2.695)^{*}$ \\
Lagged Dependent Variable & - & - & $0.566(5.818)^{*}$ \\
$\mathrm{R}^{2}$ & 0.585 & 0.906 & 0.954 \\
D-W & 1.478 & 2.674 & 1.771 \\
\hline
\end{tabular}

Figures in brackets are $t$-ratios.

*Significant at 5 percent level.

**Significant at 10 percent level. 
Non-tax Revenues: These are assumed to be exogeneously determined.

Current Expenditure: Current expenditure of Provincial Governments appears to respond quickly and strongly to larger transfers. The absence of a significant lagged variable indicates that the process of adjustment is more less, instantaneous. A one rupee increase in transfers leads to a more than 40 paisa rise in current expenditure.

Development Expenditure: The combined ADP of the Provincial Governments also appears to be linked to the size of the revenue surplus, which is likely to be larger when transfers increase. However, there is a process of lagged adjustment here indicating that, especially in the case of the smaller Provincial Governments, there are limits to absorption capacity, in terms of implementation of a larger portfolio of projects.

Results of the empirical analysis of past fiscal behaviour indicate that in the aftermath of an Award which expands the share of provinces, the consolidated fiscal deficit tends to rise because there are no corresponding cutbacks in federal current expenditure, the fall in the size of the PSDP is accomplished with some time lag, while provincial current expenditure rises rapidly in response to larger transfers. This impact is somewhat moderated by the launching of a more intensive fiscal effort through tax reforms by the Federal Government to at least partially make up for the loss in net revenue receipts. Also, provincial ADPs take some time to fully adjust upwards.

Given these contrasting behavioural responses, the net impact on the overall fiscal deficit of an Award like the 7th NFC Award is ambiguous. Based on the estimated equations, we project next the relevant budgetary magnitudes for the federal and provincial governments in the presence and in the absence of the 7th NFC Award. This will enable derivation of the impact on the combined fiscal deficit and on the deficit of the respective governments.

\section{BUDGETARY PROJECTIONS}

Table 3 presents the budgetary projections for 2010-11 with and without the 7th NFC Award. These projections are compared with the estimates announced in the Budget of 2010-11 by the Federal and the Provincial Governments.

A number of important conclusions emerge from the table. First, given the targets embodied in the on-going SBA with the IMF, the budget documents are very optimistic in projecting that the consolidated fiscal deficit will be reduced sharply to 4 percent of the GDP from 6.3 percent in 2009-10. This implies that either the NFC Award is conducive to deficit reduction or that the scaling down of the deficit will be achieved despite the award.

The first area of optimism is with regard to the growth of federal tax revenues, which are expected to rise by 26.7 percent, substantially in excess of the nominal growth in GDP of 14.4 percent expected at the time of the framing of the budget. The equation for federal tax revenues estimated in Table 1 indicates a more moderate growth of 17.6 percent, which includes an incremental fiscal effort of Rs 35 billion on top of the revenue expectation in the absence of the 7th NCF Award. 
Table 3

Projection of Consolidated Budget*

\begin{tabular}{|c|c|c|c|c|}
\hline & \multirow[b]{2}{*}{$\begin{array}{c}2009-10 \\
\text { (Revised) }\end{array}$} & \multirow[b]{2}{*}{$\begin{array}{l}\text { 2010-11 } \\
\text { (Budget) }\end{array}$} & \multicolumn{2}{|c|}{ Projections, 2010-11 } \\
\hline & & & $\begin{array}{l}\text { Without 7th } \\
\text { NFC Award }\end{array}$ & $\begin{array}{c}\text { With 7th } \\
\text { NFC Award }\end{array}$ \\
\hline (a) Revenue & 2079 & 2607 & 2437.1 & 2463.4 \\
\hline Tax Revenues & 1500 & 1907 & 1737.1 & 1763.4 \\
\hline Federal $^{\mathrm{a}}$ & 1445 & 1831 & 1665.0 & 1700.1 \\
\hline Provincial & 55 & 76 & 72.1 & 63.3 \\
\hline Non-tax Revenues & 579 & 700 & 700.0 & 700.0 \\
\hline Federal & 495 & 634 & 634.0 & 634.0 \\
\hline Provincial & 84 & 66 & 66.0 & 66.0 \\
\hline (b) Expenditure & 3040 & 3293 & 3274.1 & 3348.7 \\
\hline Current Expenditure & 2482 & 2696 & 2644.9 & 2736.2 \\
\hline Federal & 1855 & 1866 & 1897.1 & 1897.1 \\
\hline Provincial & 627 & 830 & 747.8 & 839.1 \\
\hline \multicolumn{5}{|l|}{ Development } \\
\hline Expenditure & 558 & 597 & 629.2 & 612.6 \\
\hline Federal & 299 & 257 & 345.3 & 292.6 \\
\hline Provincial & 259 & 340 & 283.9 & 319.9 \\
\hline (c) Budget Deficit & -961 & -686 & -837 & -885 \\
\hline$\%$ of GDP & -6.3 & -4.0 & -4.9 & -5.2 \\
\hline
\end{tabular}

*Without allowing for the impact of the floods.

${ }^{a}$ Including non-FBR revenues of Rs 142 billion in 2010-11.

Turning to federal current expenditure, the budget expects to contain the growth in 2010-11 to only 0.6 percent. This is to be achieved despite the higher costs of implementing the salary award of a 50 percent hike in basic pay and increase in other allowances. The estimated equation indicates somewhat more growth.

The federal budget also anticipates a fall in development spending in the PSDP of over 14 percent. However, the estimated equation for federal development expenditure reveals that the likelihood is for only a small fall in the first year after the NFC Award. Nevertheless, this is over Rs 52 billion less than the level projected in the absence of the Award.

Provincial governments have also made optimistic projections about the growth rate of their tax revenues in 2010-11 at over 38 percent. The historical evidence, as highlighted earlier, is for these governments to slacken their fiscal effort following the receipt of larger transfers. As such, the equation for provincial tax revenues indicates a more modest growth of 15 percent, with the level about Rs 9 billion less than what could have been achieved in the absence of the NFC award.

As far as provincial current expenditure is concerned, budget estimates and estimates from the relevant equation are close to each other. It is important to note that larger NFC transfers will stimulate current expenditure of provincial governments by as much as Rs 91 billion, a large part of which will go towards financing the salary hike. 
Development expenditures have been shown as rising rapidly by over 31 percent in the provincial budgets. But, as indicated above, the smaller provincial governments like Balochistan, may not be able to raise the capacity to execute a much larger development program in the short run. As such, the shortfall could be about Rs 20 billion in relation the budget estimates. However, this will still be Rs 36 billion higher than the level that would have been attained in the absence of the NFC Award. Overall, the equations used for forecasting federal and provincial revenues and expenditure indicate that the likely level of the consolidated fiscal deficit in 2010-11 is 5.2 percent of the GDP in relation to the original budgeted level of 4 percent of the GDP. We also have the conclusion that in the first year after the NFC Award the consolidated budget deficit is likely to be Rs 48 billion higher, equivalent to 0.3 percent of the GDP, than would have been the case in the absence of the NFC Award.

In terms of the extent of fiscal decentralisation, the 7th NFC Award is expected to increase the combined share of the provincial governments in public expenditure from 29 percent in 2009-10 to 35 percent in 2010-11. This is a big jump and Pakistan will approach an intermediate level of fiscal decentralisation. In particular, provincial governments will now account for the major share of development expenditure.

Table 4 indicates that the increase in the federal deficit is even larger at about 0.6 percent of the GDP following the NFC Award. This is partly compensated for by a decline in the combined fiscal deficit of provincial governments of 0.3 percent of the GDP.

Overall, we have the conclusion that the 7th NFC Award has led to some deterioration in the underlying structural fiscal deficit of the Federal and Provincial Governments combined, albeit by a relatively small magnitude of about 0.3 percent of the GDP. However, this impact could increase as the smaller provincial governments, like that of Balochistan, gear up to execute larger development programmes.

Table 4

Summary of the Deficit of the Federal and Provincial Governments

(\% of GDP)

\begin{tabular}{lcccc}
\hline & & \multicolumn{2}{c}{ Projections, } \\
\cline { 3 - 5 } & $2009-10$ & $2010-11$ & 2010-11 \\
\cline { 4 - 5 } & (Revised) & (Budget) & NFC Award & With 7th NFC \\
& -5.7 & -4.0 & -4.4 & -5.0 \\
Federal & -0.6 & 0.0 & -0.5 & -0.2 \\
Provincial & $\mathbf{6 . 3}$ & $\mathbf{- 4 . 0}$ & $-\mathbf{4 . 9}$ & $\mathbf{- 5 . 2}$ \\
Combined & & & &
\end{tabular}

\section{POLICY IMPLICATIONS}

The basic factors contributing to the rise in the fiscal deficit are the decline in the fiscal effort of Provincial Governments and a big increase in expenditure in the anticipation of larger transfers mandated by the NFC Award. One way in which this tendency can be mitigated is to provide an incentive to provincial governments as part of the Award in the form of a matching grant equal to the increase in self-financing of 
expenditure in relation to some minimum benchmark level, which will, of course, depend on the fiscal capacity of a particular provincial government, as follows:

$$
\begin{array}{llllllll}
G=\left[R_{p}+\bar{N}_{p}-\bar{E}_{p}=B_{0}\right] & \ldots & \ldots & \ldots & \ldots & \ldots & \ldots
\end{array}
$$

If and only if $G>0$

Where $G=$ additional grant, $B_{0}=$ benchmark level.

In this case

$$
E_{p}=\frac{\overline{T F}}{2} R_{p}+N_{p}+\bar{D}_{p}-\frac{B_{0}}{2} \quad \ldots \quad \ldots \quad \ldots \quad \ldots \quad \ldots
$$

Based on the process of utility maximisation of the type described earlier, we obtain

$$
R_{p}=(1-\theta)\left(y-y_{o p}\right)-\left(\frac{\theta}{2}\right) \overline{T F}-\bar{N}_{p}-\bar{D}_{p} / 2-B / 2 \quad \ldots \quad \ldots \quad \ldots
$$

A comparison with (16) reveals that in the presence of this incentive scheme the extent of reduction in fiscal effort is halved given the size of transfers, $T F$.

Similarly, we have

$$
E_{p}=(1-\theta)\left(y-y_{o}\right)+\left(\frac{1-\theta}{2}\right) T F+\frac{(1-\theta) \overline{D_{p}}}{2}-\frac{(1-\theta) B}{2}
$$

The new expenditure equation when compared with (16) shows that the increase in expenditure associated with an increase in transfers is half of what it is likely to be in the absence of the incentive.

Therefore, a matching grant linked to increase in self-financing will reduce the negative effects of the increase in transfers following an Award. It is recommended that such a scheme be put in place as part of the NFC Award, if not in the present award then in the next Award.

The 11th Finance Commission of India has incorporated the above type of incentive with a view to providing for better financial management and greater fiscal discipline. As such, 7.5 percent of the revenues to the states is to be shared on the basis of the measure of financial discipline corresponding to the ratio of own revenue receipts to total revenue expenditure.

\section{CONCLUSIONS}

The paper has analysed the impact of the 7th NFC Award on the size of the consolidated fiscal deficit of the Federal and Provincial Governments in 2010-11, the first year of implementation of the Award. A behavioural asymmetry is observed whereby federal current expenditure is inflexible downwards in the face of a decline in resources while provincial current expenditures show a big and rapid response to larger transfers. This asymmetry is the basic cause of any increase in the fiscal deficit although this is partially mitigated by enhanced fiscal effort by the federal governments and some lag in the rise in development spending by the provinces. Overall, it is estimated that the 
consolidated fiscal deficit is higher by about 0.3 percent of the GDP due to the behavioural responses associated with the Award. The paper proposes an incentive scheme to reduce the negative effects arising from an Award which increases the share of the provinces.

\section{REFERENCES}

Ghaus, A. F. A. and Hafiz A. Pasha (1994) Dynamic Budgetary Consequences of the 1991 NFC Award. The Pakistan Development Review 33:4.

Henderson, James M. (1968) Local Government Expenditures: A Social Welfare Analysis. The Review of Economics and Statistics 50.

Slack, Enid (1980) Local Fiscal Response to Inter-governmental Transfers. The Review of Economics and Statistics 62. 